\title{
COMPARISON OF STANDARD AND TUBELESS PERCUTANEOUS NEPHROLITHOTOMY IN A TERTIARY CARE HOSPITAL IN EASTERN NEPAL
}

Thakur $D K^{1^{*}}$

\section{Affiliation}

1. Consultant Urologist, Department of Surgery, Birat Medical College Teaching Hospital, Tankisinuwari, Morang

\section{ARTICLE INFO}

\section{Article History}

Received : 15 March, 2018

Accepted : 2 April, 2018

Published : 30April, 2018

(C) Authors retain copyright and grant the journal right of first publication with the work simultaneously licensed under Creative Commons Attribution License CC - BY 4.0 that allows others to share the work with an acknowledgment of the work's authorship and initial publication in this journal.

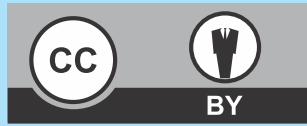

ORA 58

DOI: http://dx.doi.org/10.3126/bjhs.v3i1.19761

\section{* Corresponding Author \\ Dr Deepak Kumar Thakur Consultant Urologist \\ Department of Surgery (Urology) \\ Birat Medical College Teaching Hospital \\ Tankisinuwari, Morang \\ Email:yoursdeepak2000@gmail.com \\ https://orcid.org/0000-0001-5189-3070}

\section{Citation}

Thakur DK. Comparison of Standard and Tubeless Percutaneous Nephrolithotomy in a Tertiary Care Hospital in Eastern Nepal. BJHS 2018;3(1)5:366 - 369.

\section{ABSTRACT}

\section{Introduction}

PCNL is a minimally invasive technique for treatment of renal and upper ureteral stones and has gone modifications like tubeless, total tubeless, mini and ultra mini PCNL.

\section{Objective}

To compare efficacy, safety and outcome of tubeless PCNL with standard PCNL.

\section{Methodology}

The study was conducted from January 2017 to December 2017 involving 50 patients undergoing PCNL randomized into standard PCNL group (S group) and tubeless PCNL group (T group) each arm containing 25 patients. Patients with congenital renal anomalies, solitary functioning kidney, previous renal surgery, clinically significant residual stones/fragments, perforation of pelvi-calyceal system and requiring conversion were excluded. Data analyzed using SPSS 20, chi-square test and Student's t test was used where appropriate. A $p$-value of $<0.05$ was considered significant.

\section{Results}

Mean age, mean stone size, preoperative hemoglobin level and creatinine level in group $S$ and $T$ were comparable. Similarly, postoperative hemoglobin level and creatinine level in groups $\mathrm{S}$ and $\mathrm{T}$ were comparable. The mean operating time in group $S$ was $99.38 \pm 16.24 \mathrm{~min}$ and $89.38 \pm 12.27 \mathrm{~min}$ in group $T(p=0.02)$. Postoperatively, VAS in group $S$ was $5.25 \pm 0.94$ and $2.88 \pm 1.68$ in group $T(p<0.001)$. Complications occurred in 9 patients in S group as postoperative anemia (hemoglobin $<10 \mathrm{gram} / \mathrm{dl}$ )-3 cases, superficial surgical site infection- 4 and urine leak- 2 while it was seen in 3 patients in T group as stoma site hematoma- 2 and anemia- $1(p=0.04$ ). Three patients in group $S$ and 1 patient in group T respectively required transfusion $(p=0.82)$. Postoperative analgesic requirement in $\mathrm{S}$ and $\mathrm{T}$ groups were $13.08 \pm 2.39$ and $9.03 \pm$ 2.44 grams of paracetamol respectively $(p<0.001)$. The hospital stay was $3.79 \pm 0.58$ days in S group and $2.54 \pm 0.50$ days in T group $(\mathrm{p}<0.001)$.

\section{Conclusion}

Tubeless PCNL is a safe option in selected cases. It is associated with significantly less postoperative pain, analgesic requirement, postoperative complication and shorter duration of hospital stay minimizing treatment cost.

\section{KEYWORDS}

Renal stone, standard PCNL, tubeless PCNL 


\section{INTRODUCTION}

Nephrolithiasis is a common condition affecting about 10\% of the population. ${ }^{1}$ The incidence and prevalence of stone disease has been increasing over time around the world. ${ }^{2}$ About $70 \%$ of the patients affected by nephrolithiasis experience recurrence. ${ }^{1}$ Various treatment modalities are available for the renal stones which include medical management, extracorporeal shock wave lithotripsy (ESWL), percutaneous nephrolithotomy (PCNL), open renal surgery and laparoscopic or robotic surgery. Since its first description in 1976 by Fernströmand Johansson, PCNL has developed into a mainstream urologic approach for management of large renal stones. ${ }^{3,4}$

The Standard PCNL include percutaneous access to collecting system, dilation of the tract, nephroscopy, stone fragmentation and removal and placement of ureteral stent and nephrostomy tube. But insertion of nephrostomy tube can cause complications like more pain, increase duration of hospital stay and increase treatment cost. Tubeless PCNL was developed as an alternative method to decrease complications associated with standard PCNL., ${ }^{5,6}$ In tubeless PCNL, no nephrostomy tube is inserted. 'The aim of this study was to compare outcome of standard andtubeless PCNL.

\section{METHODOLOGY}

The study was conducted in the Urology unit, Department of Surgery, Birat Medical College-Teaching Hospital, Biratnagar, Nepal over a period of one year (January 2017 to December 2017). Fifty patients were included in the study each arm containing 25 patients. Patients with congenital renal anomalies, previous renal surgery, clinically significant residual stones/fragments, perforation of pelvi-calyceal system, requiring conversion from tubeless to standard PCNL and solitary functioning kidney were excluded. One patient from the standard PCNL group was excluded as he required staged procedure and one patient from tubeless group was excluded because of intraoperative bleeding requiring nephrostomy tube placement ( Fig. 1). The study was approved by hospital administration.

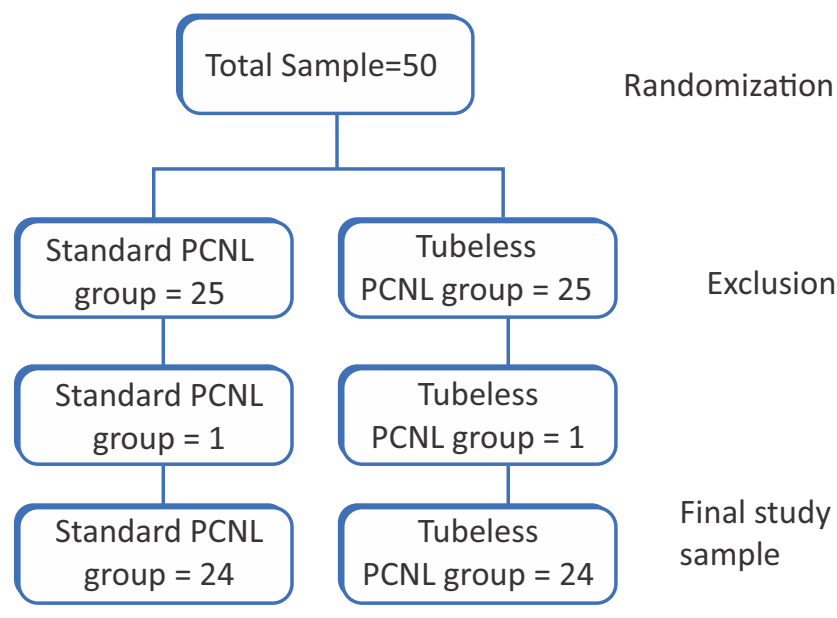

Figure 1: Consort Diagram
After informed consent and preoperative preparation, patients were randomized into two groups- standard PCNL group (S) and tubeless PCNL group (T) each having 25 patients by computer generated random numbers. One patient from each group was excluded because of staged procedure and bleeding mandating nephrostomy tube respectively. All patients underwent PCNL using standard protocol. Baseline characteristics, intraoperative events andoperating time were recorded. Patients in $\mathrm{S}$ group received $22 \mathrm{~F}$ nephrostomy tube postoperatively in addition to $6 \mathrm{~F}, 26 \mathrm{~cm}$ both end open double J stent while nephrostomy tube was omitted in the patients in T group. Stone clearance was assessed by postoperative KUB (Kidney-ureter-bladder) $\mathrm{x}$-ray. In $\mathrm{S}$ group, nephrostomy tube was removed on first postoperative day after confirmation of no clinically significant residual fragment and foley's cather was removed on second postoperative day in both groups. Postoperative pain was assessed by visual analogue scale (VAS), analgesic requirement (Paracetamol $1 \mathrm{gram} /$ dose), postoperative complications and hospital stay was recorded. Double J stent was removed after 2 weeks in both groups.

\section{Statistical Analysis}

Data were analysed using SPSS 20, chi-square test and Student's $t$ test were used where appropriate. A p-value of $<0.05$ was considered significant.

\section{RESULTS}

Fifty patients were included in the study, 25 patients in each arm. One patient from each group was excluded due to various reasons( Fig.1). The ratio of male and female in group $S$ and T was 12:12 and 11: 13 respectively. The mean age was $37 \pm 11.70$ years in group $S$ and $37 \pm 11.90$ years in group $T(p=0.96)$. The mean stone size, preoperative hemoglobin level and creatinine level in group $S$ and $T$ were $2.35 \pm 0.84 \mathrm{~cm}, 2.15 \pm 0.62 \mathrm{~cm}(p=0.33), 12.17 \pm 1.04 \mathrm{gm} / \mathrm{dl}$, $15.15 .77 \pm 1.05 \mathrm{gm} / \mathrm{dl}(p=0.36)$ and $1.00 \pm 0.20 \mathrm{mg} / \mathrm{dl}, 1.10 \pm$ $0.20 \mathrm{mg} / \mathrm{dl}(\mathrm{p}=0.12)$ respectively ( Table 1$)$.

\begin{tabular}{|l|l|l|l|}
\hline \multicolumn{3}{|c|}{ Table 1: Baseline Characteristics } \\
\hline Characteristics & $\begin{array}{l}\text { Standard } \\
\text { PCNL group(S) }\end{array}$ & $\begin{array}{l}\text { Tubeless } \\
\text { PCNL group (T) }\end{array}$ & P value \\
\hline $\begin{array}{l}\text { Age (years) } \\
\text { (Mean } \pm \text { SD) }\end{array}$ & $37 \pm 11.70$ & $37 \pm 11.90$ & 0.96 \\
\hline M:F & $12: 12$ & $11: 13$ & - \\
\hline $\begin{array}{l}\text { Stone size (cm) } \\
\text { (Mean } \pm \text { SD) }\end{array}$ & $2.35 \pm 0.84$ & $2.15 \pm 0.6$ & 20.33 \\
\hline $\begin{array}{l}\text { Hemoglobingm/dl } \\
\text { (Mean } \pm \text { SD) }\end{array}$ & $12.17 \pm 1.04$ & $15.15 .77 \pm 1.05$ & 0.36 \\
\hline $\begin{array}{l}\text { Creatinine mg/dl } \\
\text { (Mean } \pm \text { SD) }\end{array}$ & $1.00 \pm 0.20$ & $1.10 \pm 0.20$ & 0.12 \\
\hline
\end{tabular}

Postoperatively, VAS in group $S$ was $5.25 \pm 0.94$ and $2.88 \pm 1.68$ in group $T(p<0.001)$. Similarly, hemoglobin level and creatinine level in groups $S$ and T were $11.48 \pm 1.04 \mathrm{gm} /$ $\mathrm{dl}, 11.17 \pm 1.27 \mathrm{gm} / \mathrm{dl}(\mathrm{p}=0.35)$ and $0.97 \pm 0.23 \mathrm{mg} / \mathrm{dl}, 1.07 \pm$ $0.17 \mathrm{mg} / \mathrm{dl}(p=0.85)$ respectively. The mean operating time 
in group S was $99.38 \pm 16.24 \mathrm{~min}$ and $89.38 \pm 12.27 \mathrm{~min}$ in group $\mathrm{T}(\mathrm{p}=0.02)$. Complications occurred in 9 patients in $\mathrm{S}$ group as postoperative anemia (hemoglobin $<10$ gram/dl)3 cases, superficial surgical site infection-4 and urine leak- 2 while it was seen in 3 patients in T group as stoma site hematoma- 2 and anemia-1 $(p=0.04)$. Three patients in group $\mathrm{S}$ and 1 patient in group $\mathrm{T}$ respectively required transfusion ( $p=0.82)$. Postoperative analgesic requirement in $S$ and T groups were $13.08 \pm 2.39$ and $9.03 \pm 2.44$ grams of paracetamol respectively $(p<0.001)$. The hospital stay was $3.79 \pm 0.58$ days in S group and $2.54 \pm 0.50$ days in T group $(p<0.001)$ [Table 2].

\begin{tabular}{l|l|l|l|}
\hline \multicolumn{3}{|l}{ Table 2: Postoperative parameters } \\
\hline Characteristics & $\begin{array}{l}\text { Standard } \\
\text { PCNL group(S) }\end{array}$ & $\begin{array}{l}\text { Tubeless } \\
\text { PCNLgroup (T) }\end{array}$ & P value \\
\hline $\begin{array}{l}\text { VAS (Mean } \pm S D) \\
\text { Hemoglobin (gm/dl) } \\
\text { (Mean } \pm \text { SD) }\end{array}$ & $11.25 \pm 0.94$ & $2.88 \pm 1.68$ & $<0.001$ \\
\hline $\begin{array}{l}\text { Creatinine (mg/dl) } \\
\text { (Mean } \pm \text { SD) }\end{array}$ & $0.97 \pm 0.23$ & $1.07 \pm 0.17$ & 0.85 \\
\hline $\begin{array}{l}\text { Operating time(min) } \\
\text { (Mean } \pm \text { SD) }\end{array}$ & $99.38 \pm 16.24$ & $89.38 \pm 12.27$ & 0.02 \\
\hline $\begin{array}{l}\text { Analgesic } \\
\text { required (gram) } \\
\text { (Mean } \pm \text { SD) }\end{array}$ & $13.08 \pm 2.39$ & $9.03 \pm 2.44$ & $<0.001$ \\
\hline $\begin{array}{l}\text { Hospital stay (days) } \\
\text { (Mean } \pm \text { SD) }\end{array}$ & $3.79 \pm 0.58$ & $2.54 \pm 0.50$ & $<0.001$ \\
\hline
\end{tabular}

\section{DISCUSSION}

This study aimed at comparing outcome of patients undergoing standard PCNL and tubeless PCNL performed by a single urologist in a tertiary care hospital in the eastern part of Nepal.

The mean age of patients in this study was 37 years in both groups which is comparable with the studies of Jagadeeshwar et al (39.5 years in group $S$ and 33.9 years in group $T$ ) and Gupta et al (32.6 years in S group and 34.4 years in $T$ group). ${ }^{8,9}$ The mean stone size in the both studies and both groups were $3.1 \mathrm{~cm}, 2.8 \mathrm{~cm}$ and $3.6 \mathrm{~cm}, 3.2 \mathrm{~cm}$ respectively slightly larger than this study but it was comparable in both groups.

In this study, the mean operating time was 99.38 minutes in $\mathrm{S}$ group and 89.38 minutes in $\mathrm{T}$ group which was significantly shorter $(p=0.02)$. Jagadeeshwar et al reported 42.8 minutes in standard PCNL group and 35 minutes in tubeless group, shorter than this study but significantly shorter in tubeless group. ${ }^{8}$ Gupta et al reported shorter operating time in tubeless group but the difference was not statistically significant. Similary, Wang et al in a meta-analysis of six studies could not found statistically significant difference in operating time in both groups. ${ }^{9,10}$ However, in another meta-analysis by Xun and colleague involving 14 RCTs and 1148 patients, they reported significantly shorter operating time in tubeless PCNL arm consistent with the present study. ${ }^{11}$

The VAS for pain on first postoperative day was lower in tubeless PCNL group ( 2.88 vs 5.25 ) to the level of statistical significance $(p<0.001)$ in present study. The result is consistent with other similar studies. ${ }^{10-12}$

Analgesic requirement ( $1 \mathrm{gm} /$ dose of paracetamol) in tubeless group was significantly less compared to standard PCNL group $(p<0.001)$. This is similar to other studies though they used different analgesics ranging from opioids to nonsteroidal anti-inflammatory drugs. ${ }^{8-12}$

Preoperative hemoglobin and serum creatinine were comparable in both groups ( $p=0.36$ and 0.12 ). Postoperatively also there was no significant change in hemoglobin and creatinine level in both groups $(p=0.35$ and 0.85$)$ indicating omitting nephrostomy tube is not associated with increased tendency of bleeding and impaired renal drainage., 8,,11

Out of 24 cases, complications occurred in 9 cases in S group and 3 cases in $T$ group $(p=0.04)$. Three cases required postoperative blood transfusion, 4 cases had superficial surgical site infection and 2 cases had urine leak from nephrostomy site requiring re-suturing of the stoma in $\mathrm{S}$ group. Similarly, 2 cases developed stoma site hematoma requiring evacuation and 1 case required postoperative transfusion in T group. The transfusion requirement in both groups was not statistically significant $(p=0.32) .^{12,13}$

Similarly, duration of hospital stay in tubeless group was significantly shorter than in patient with standard PCNL group ( $p<0.001)$. This finding is consistent with other similar studies comparing tubeless PCNL with standard PCNL. ${ }^{8-12}$

\section{CONCLUSION}

Tubeless PCNL is a safe option in selected cases. It is associated with significantly less postoperative pain, analgesic requirement, postoperative complication and shorter duration of hospital stay minimizing treatment cost.

\section{RECOMMENDATION}

High quality larger trials with longer follow-up is recommended.

\section{LIMITATION OF THE STUDY}

The study is limited by less number of patients and observer bias as it was not blinded.

\section{ACKNOWLEDGMENTS}

I am thankful to Dr Tara Kafle, Department of Community Medicine, Birat Medical College for her support and guidance during the statistical analysis.

\section{CONFLICT OF INTEREST}

None. 


\section{REFERENCES}

1. Moe OW. Kidney stones: pathophysiology and medical management.Lancet2006; 367: 333-344, DOI: 10.1016/S01406736(06)68071-9.

2. Romero V, Akpinar $\mathrm{H}$ and Assimos DG. Kidney stones: a global picture of prevalence, incidence, and associated risk factors. Rev Urol 2010;12:e86-96. PMID: 20811557.

3. Fernström I and Johansson B. Percutaneous pyelolithotomy. A new extraction technique. Scand J Urol Nephrol. 1976;10: 257-9. PMID: 1006190.

4. Delnay KM and Wake RW. Safety and efficacy of tubeless percutaneousnephrostolithotomy. World J Urol 1998;16:375-7.

5. Limb J and Bellman GC. Tubeless percutaneous renal surgery:review offirst 112 patients.Urology2002; 59: 527-531. DOI:10.1016/S0090-4295(01)01627-2.

6. Bellman GC, Davidoff R, Candela J, Gerspach J, Kurtz Sand Stout L. Tubeless percutaneous renal surgery.J Urol1997;157: 1578-1582. DOI: 10.1016/S0022-5347(01)64799-2.

7. Boylu U. Tubeless percutaneous nephrolithotomy: a prospective feasibility study and review of previous reports.BJUInt2006; 97: 868. DOI: 10.1111/j.1464-410X.2006.06163_3.x.
8. T. Jagadeeshwar, Ravi Jahagirdhar, A. Bhagawan, N. Rama Murthy, G. Ravichandar, G. Mallikarjun et al.P. Naveen "Comparative Study of 'Percutaneous Nephrolithotomy Placement' Versus Percutaneous Nephrolithotomy without Nephrostomy Placement (Tubeless PCNL)". Journal of Evolution of Medical andDental Sciences 2014; Vol. 3, Issue 61, Page: 13551-13556.

9. Gupta NP, MishraS, Suryawanshi M, Seth A, Kumar R. Comparision of standard PCNL with tubeless PCNL. J Endourol. 2008,22(7): 1441-6. DOI: 10.1089/end.2007.0338.

10. Wang, J., Zhao, C., Zhang, C., Fan, X., Lin, Y. and Jiang, Q.Tubelessvs standard percutaneous nephrolithotomy: a meta-analysis. BJU International. 2012; 109(6): 918-924. PMID: 21883839.

11. Xun $Y$, Wang $Q$, Hu H, Lu Y, Zhang J, Qin B and Geng $Y$ et al. Tubeless versus standard percutaneous nephrolithotomy: an update metaanalysis. BMC Urol. 2017;17(1):102. DOI: 10.1186/s12894-0170295-2.

12. Agrawal MS, Agrawal M, Gupta A, Bansal S, Yadav A, Goyal J.A randomized comparison of tubeless and standard percutaneous nephrolithotomy. J Endourol. 2008 ;22(3):439-42. DOI: 10.1089/end.2007.0118.

13. Lojanapiwat B. Does previous open nephrolithotomy affect the efficacy and safety of tubeless percutaneous nephrolithotomy? J Urollnt 2010; 85: 42-6. DOI: 10.1159/000318188. 